\title{
TONIO HÖLSCHER
}

\section{Mythen als Exempel der Geschichte}

Eine Untersuchung über die Rolle der Mythen in der Bildkunst Roms muß von einigen sattsam bekannten, aber unumgänglichen Denkmälern ausgehen. ${ }^{1}$ Es wird sich immerhin zeigen, daß dieser Charakter der "Sattsamkeit" ein wesentlicher Zug des römischen Staatsmythos ist.

Der Haupteingang zur Ara Pacis ${ }^{2}$ wird seitlich von zwei Reliefbildern mit Szenen aus der Vorgeschichte Roms eingefaßt: rechts, im Süden, Aeneas mit Iulus Ascanius beim Opfer der lavinischen Sau an die Penaten; links, im Norden, die römische Wölfin mit Romulus und Remus, beobachtet von Mars und Faustulus. Die beiden Szenen sind inhaltlich eng mit dem weiteren Bildprogramm der Anlage verklammert. Zu seiten des zweiten Eingangs an der Rückseite stehen komplexe Allegorien: im Süden Tellus Italia mit den Fruchtbarkeit spendenden Aurae, bezogen auf Aeneas, der mit dem Prodigium der Sau eben dies friedvoll idyllische Italien entdeckt und dort den Habitus frommer Götterverehrung begründet hatte; im Norden Roma auf Waffen sitzend, wohl zwischen den Genien des Senats und des römischen Volkes, auf der Seite der mythischen Gründer der Stadt und ihres Vaters Mars, die für den Kriegsruhm und die ewige Unbezwingbarkeit der Römer stehen. Der Bezugspunkt dieses Konzepts in der Gegenwart wird durch die Friese an den beiden Längswänden deutlich gemacht, an denen die feierliche Zeremonie der constitutio arae mit der Inauguration durch den Kaiser, unter Teilnahme der hohen Priesterschaften und der kaiserlichen Familie, geschildert wird. Hier sind die Figuren so organisiert, daß der Princeps und die wichtigeren Repräsentanten

\footnotetext{
${ }^{1}$ Übergreifende Arbeiten zu dem Thema liegen aus dem Bereich der Bildkunst nicht vor. Unergiebig ist P. Aichholzer, Darstellungen römischer Sagen, Wien 1983.

${ }^{2}$ Die Deutung verschiedener Szenen und Figuren an der Ara Pacis ist bekanntlich kontrovers. Für die grundsätzliche Feststellung des politischen Bildsystems von Mythos, Allegorie und gegenwärtigem Zeremoniell, um die es hier geht, sind diese Kontroversen jedoch irrelevant. Zur Orientierung über den gegenwärtigen Stand: G. Moretti, Ara Pacis Augustae, Rom 1948; E. Simon, Ara Pacis Augustae, Tübingen 1963; M. Torelli, Typology and Structure in Roman Historical Reliefs, Ann Arbor 1982, 27-61; E. La Rocca, Ara Pacis Augustae, Rom 1983; S. Settis, Die Ara Pacis, in: AA. VV. (1988) 400-426.
} 
des Hofes an der Südseite, d.h. Aeneas und Italia zugeordnet, erscheinen: Augustus und sein mythischer Ahnherr sind durch das Thema der Götterverehrung wie durch den Typus ihrer Gestalten deutlich aufeinander bezogen, und Livia ist in ihrer weiblichen Schönheit mit Tellus verbunden. Die mehr anonymen Priesterschaften, die die Nordseite beherrschen, verkörpern dagegen mehr das römische Volk und seine Führungsschicht, sinnvoll zwischen den mythischen Gründern und den idealen Repräsentanten der Stadt. Mythos und Allegorie sind perspektivisch auf die Gegenwart bezogen. Auf allen drei Ebenen erweisen sich pietas und Glücksfülle einerseits, virtus und militärischer Ruhm andererseits als Grundpfeiler der römischen Herrschaft.

Die Gründungsmythen Roms sind in diesem Denkmal in sehr plakativer Weise politisch funktionalisiert. Die Überlegungen, die sich daran anschließen, gelten drei Fragen: Welches sind die Merkmale dieser politischen Aktualisierung von Mythen? Wo und unter welchen Bedingungen ist sie entstanden? Und welche spezifische Rolle haben die politischen Mythen in Rom gespielt?

Grundsätzlich handelt es sich um Phänomene, die nicht spezifisch für Rom sind - wie überhaupt Rom in bezug auf die Mythen kaum eine grundsätzliche Sonderstellung einnimmt. Wenn man sich einmal von der eingewurzelten Vorstellung polarer struktureller Gegensätze zwischen Griechenland und Rom löst, die in der Klassischen Archäologie, aber auch in anderen Bereichen der Altertumswissenschaft eine unheilvolle Rolle gespielt hat ${ }^{3}$, und Rom vielmehr als eine Stadt am Rand der griechisch geprägten Kultur sieht, dann ergibt sich ein sinnvoller Rahmen für das Verständnis seiner Mythen: Wie in anderen Städten, so wurden auch hier früher oder später Gründungsmythen der eigenen Stadt ausgebildet und mythische Aitia für die lokalen religiösen und sozialen Institutionen gefunden; darüberhinaus wurden die großen, allgemein griechischen Mythen rezipiert und zum Teil - so die Taten des Herakles oder die Zerstörung Troias mit ihren Folgen auf die eigene Stadt ausgerichtet.

Gegenüber dieser primären Stufe der Mythen ist die politische Funktionalisierung, wie sie an der Ara Pacis in voller Ausprägung begegnet, ein grundsätzlich

${ }^{3}$ Dazu O.J. Brendel, Mem. Am. Acad. Rome 21 (1953) 32-41. 41-52 (wieder in: Ders., Prolegomena to the Study of Roman Art, New Haven/London 1979, 47-68. 68-92, dazu 156-161); S. Settis, ,Ineguaglianze“ e continuità: un'immagine dell' arte romana, in: O.J. Brendel, Introduzione all'arte romana, Turin 1980, bes. 175; A. H. Borbein, Gerhard Rodenwaldts Bild der römischen Kunst, in: E. Gabba - K. Christ (Hgg.), L'impero romano fra storia generale e storia locale (Biblioteca di Athenaeum 16), Como 1991, 189-192. 
neuer Schritt. Die Mythen erhielten in diesem Kontext einen deutlich anderen Sinn, als sie zu ihrer Entstehungszeit gehabt hatten. Auch dies gilt aber in vergleichbarer Weise schon für Griechenland, wo Mythen seit der Zeit um 500 v. Chr. in neuer Weise für die Politik vereinnahmt werden konnten. Hier wie in Rom bekamen die Geschichten aus der mythischen Vorzeit eine sekundäre Sinnschicht, die eine grundsätzliche Entfernung vom primären Mythos anzeigt.

Die Forschung der letzten Generationen über den Mythos, deren primäres Interesse weitgehend auf die Entstehung und Ur-Bedeutung der Mythen konzentriert war, hat zum Verständnis solcher sekundärer Sinnschichten noch keinen ausreichenden theoretischen Rahmen entwickelt. ${ }^{4}$ Dieses Defizit prägt vor allem neuere Arbeiten über Mythos und Geschichte bzw. Politik in der griechischen Bildkunst. ${ }^{5}$

Darüber hinaus wurde gerade in den wichtigsten und einflußreichsten Konzepten ein grundsätzlicher Aspekt der primären Mythen, der für die Rezeption und Adaption in historischer Zeit wesentlich war, wenig beachtet: Ob man Mythen aus Ritualen herleitete, auf soziale Strukturen oder Verhaltensregeln bezog, als Ausdruck psychischer Archetypen deutete oder als elementare Handlungsmuster verstand - im besten Fall haben solche Erklärungsweisen einen impliziten Sinn, nicht aber die explizite Funktion und Bedeutung der Mythen erfaßt. Denn die Mythen, als ,traditionelle und bedeutsame Erzählungen', haben grundsätzlich nicht derartige strukturelle, konstante oder iterative Phänomene zum Thema, sondern sie berichten in ihrer primären Sinnebene immer von einzigartigen Gestalten und Vorgängen. Sie sollen nicht Normen sichern, sondern das Einmalige im Gedächtnis halten. Die Frage nach der Bedeutung der Mythen für die Antike führt also weniger auf implizite soziale, religiöse oder psychische Strukturen, als vielmehr auf die explizite Narrativität der mythischen Geschichten.

Dies ist aber auch die Grundlage, auf der die griechischen Mythen historisch und politisch adaptierbar wurden. Denn auch die griechische Historie war von Anbeginn auf außergewöhnliche und einmalige Werke und Taten ausgerichtet. In diesem Sinne und in diesem Rahmen konnten die Mythen zu Exempla für die Gegenwart werden.

${ }^{4} \mathrm{Da} \mathrm{B}$ heute, und insbesondere für Rom, die Frage nach den Erfindungen und Ursprüngen durch die nach der Rezeption und Wirkung - d.h. nach der Funktion - der Mythen ergänzt werden muß, betont zu Recht W. Burkert, oben S. $19 \mathrm{f}$.

${ }^{5}$ Thomas (1976), mit der Rez. von T. Hölscher, Gnomon 52 (1980) 358-362; H. Meyer, Kunst und Geschichte, München 1983 (dazu leider keine Rez.); W. Schindler, Mythos und Wirklichkeit in der Antike, Berlin 1987; H. Knell, Mythos und Polis, Darmstadt 1990. 
In den mythischen Bildern des Aeneas und des Romulus sind zwei Aspekte vereinigt, die die Grundfaktoren aller politischen Mythen bilden: die genealogische und die ideelle bzw. exemplarische Bedeutung. ${ }^{6}$

Der Aspekt der Genealogie geht in archaische Zeit zurück. Er umfaßt sowohl die Vorfahren im präzisen Sinne bis zu den mythischen Ahnherren berühmter Familien als auch die Vorgänger, d.h. die früheren Mitglieder derselben Gemeinschaft im weiteren Sinne bis zu den mythischen ,Gründern' von Städten und Staaten. Die Berufung auf Vorfahren und Gründer - etwa die Herleitung der Peisistratiden von Neleus oder der Athener von Erechtheus - und die Begründung gegenwärtiger Positionen und Ansprüche auf solche Filiation faßt Vorrang als festen Besitz auf, der von Generation zu Generation vererbt wird. Dagegen spielt die inhaltliche Definition solcher Positionen und Ansprüche dabei nur eine sekundäre, implizite Rolle. Zwar sehen die gegenwärtigen ,Nachfolger' sich auch durch eine gemeinsame Wertewelt mit den Vorläufern verbunden, aber die Betonung liegt auf der direkten Nachfolge, die bestimmte Personen, Gruppen oder Staaten mit dem mythischen Vorläufer personell verbindet und sie dadurch vor anderen Personen, Gruppen oder Staaten auszeichnet.

Auch die ideelle Bedeutung der Mythen beruht auf alten archaischen Wurzeln. Jeder Mythos ist von Anbeginn Ausdruck von Vorstellungen, Interessen und Perspektiven der gegenwärtigen Gesellschaft, die ihn trägt. Die Vasenbilder des 7. und 6. Jahrhunderts v. Chr. mit den Abenteuern des Odysseus haben ihre Aktualität in der frühen Seefahrt zu fernen unheimlichen Ländern, die vielfältigen Bilder des Herakles aus archaischer Zeit formulieren ein Leitbild persönlicher Aktionskraft, das für den archaischen Adel von zentraler Bedeutung war. Voraussetzung für die Entstehung und Tradition solcher Mythen ist eine relativ stark ausgebildete kollektive Wertewelt und Selbstauffassung, wie sie wiederum für den Adel der archaischen Poleis charakteristisch ist. Der Rang solcher Heroen besteht nicht im Besitz vererbbarer Privilegien, genealogische Verbindungen bis in die Gegenwart spielen keine entscheidende Rolle. Die Vorbildlichkeit beruht auf exemplarischem Heldentum, auf persönlichen Leistungen und Eigenschaften, die zum ideellen Muster für ebenso persönliche Einstellungen und Leistungen werden.

Es ist klar, daß diese Kategorien der Genealogie und der ideellen Bedeutung sich zueinander nicht exklusiv verhalten, sondern in den einzelnen Mythen oft miteinander verbunden auftreten. Dennoch behalten sie heuristischen Wert für die Erkenntnis der Strukturen des aktuellen Gebrauchs von Mythen.

Von Anbeginn, zumal bei mündlicher Tradierung, waren die griechischen My-

${ }^{6}$ Die folgenden Überlegungen können hier nur in knapper Zusammenfassung vorgetragen werden. Ausfuihrlich demnächst an anderer Stelle. 


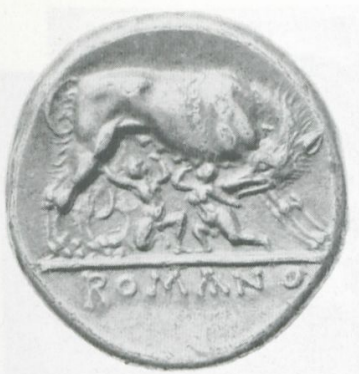

Abb. 1 Didrachme (Rs.): Wölfin und Zwillinge

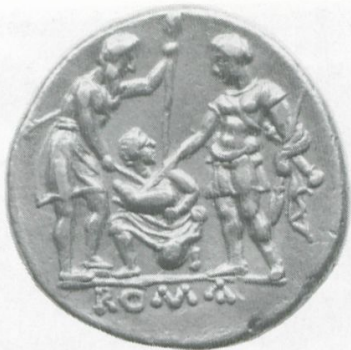

Abb. 2 Gold-Stater (Rs.): Bündnis zwischen Aeneas und Latinus

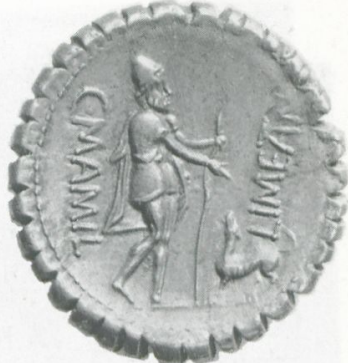

Abb. 3 Denar des

C. Mamilius Limetanus

(Rs.): Ulysses

Abb. 4-5

Denare des

L. Plautius Hypsaeus

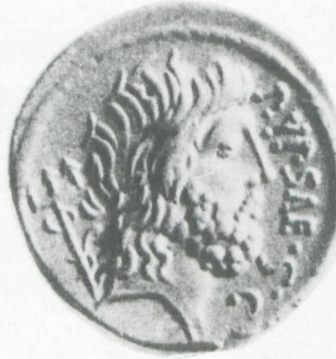

Abb. 4 Vs.: Neptunus

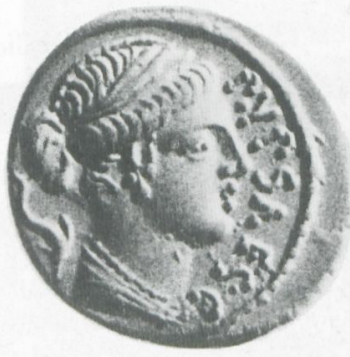

Abb. 5 Vs.: Leuconoe

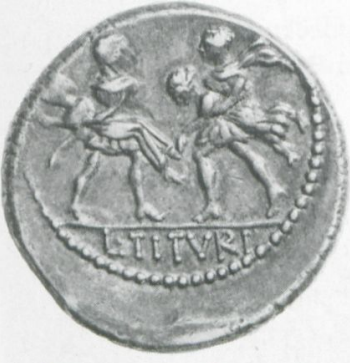

Abb. 6 Rs.: Raub der Sabinerinnen

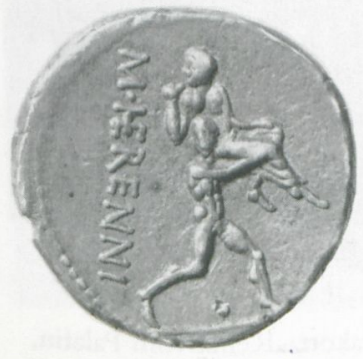

Abb. 9 Denar des

M. Herennius (Rs.): Einer der Brüder von Catane
Abb. 6-8 Denare des L. Titurius Sabinus

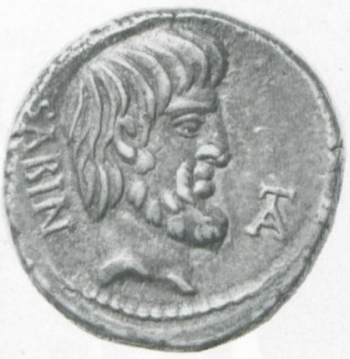

Abb. 7 Vs.: Porträt des Titus Tatius

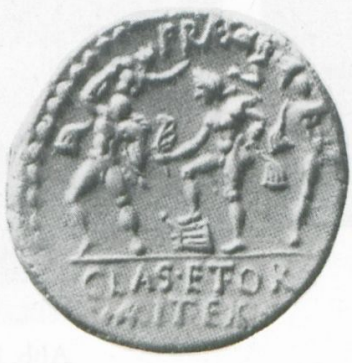

Abb. 10 Denar des Sex. Pompeius (Rs.): Brüder von Catane

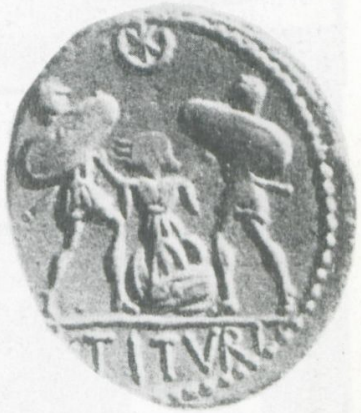

Abb. 8 Rs.: Bestrafung der Tarpeia

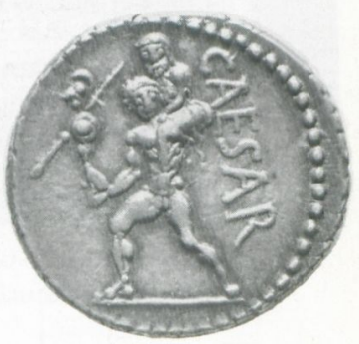

Abb. 11 Denar des C. Iulius Caesar (Rs.): Aeneas mit Anchises 


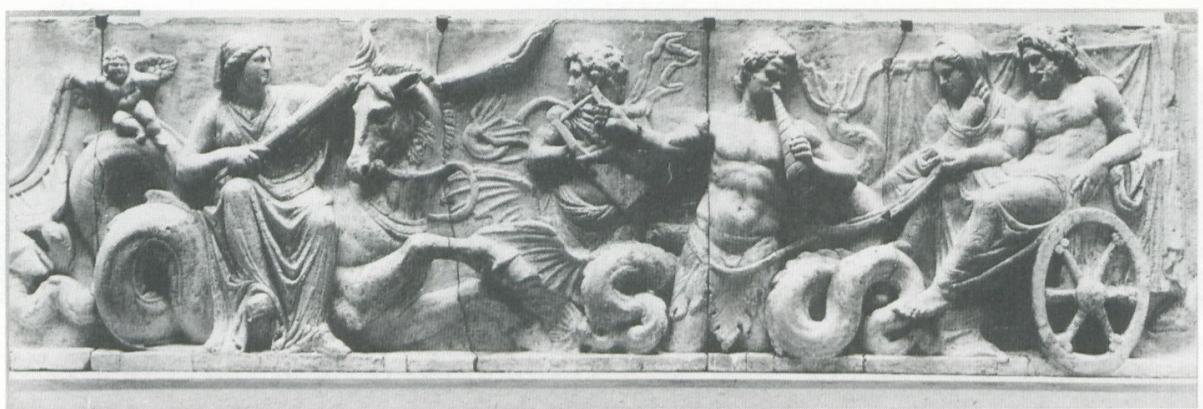

Abb. 12 Censoren-Denkmal München-Paris (Ausschnitt), München, Glyptothek: Hochzeitszug des Neptun und der Salacia

Abb. 13-14 Fries der Basilica Aemiliana, Rom, Antiquario Forense

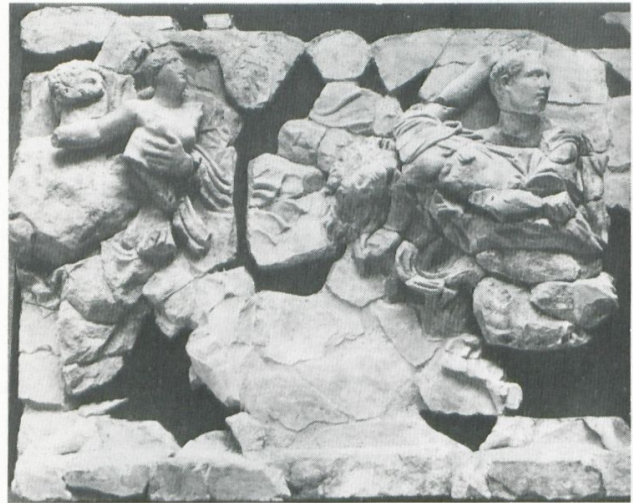

Abb. 13 Raub der Sabinerinnen

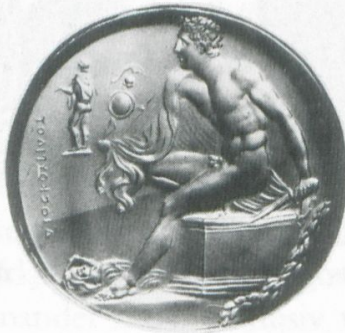

Abb. 15 Karneol,

Chatsworth, Duke of

Devonshire: Diomedes mit dem Palladium

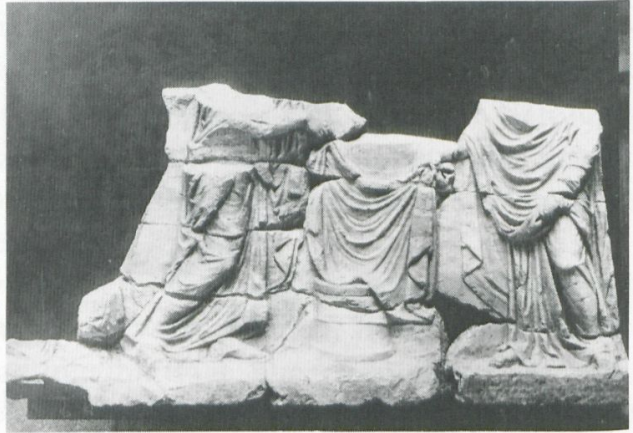

Abb.14 Aufdeckung der Ciste mit den Penaten (?)

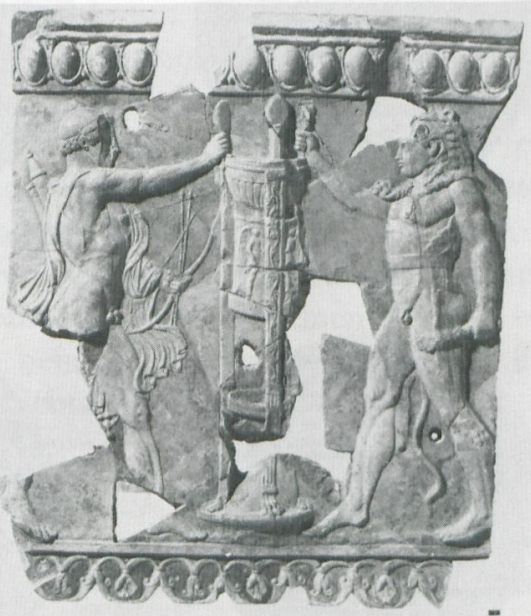

Abb.16 Terrakotta-Relief vom Palatin, Rom, Antiquario Palatino: Hercules und Apollo im Streit um den Dreifuß 
Abb. 17-20 Altar, Vatican, Museo Gregoriano Profano

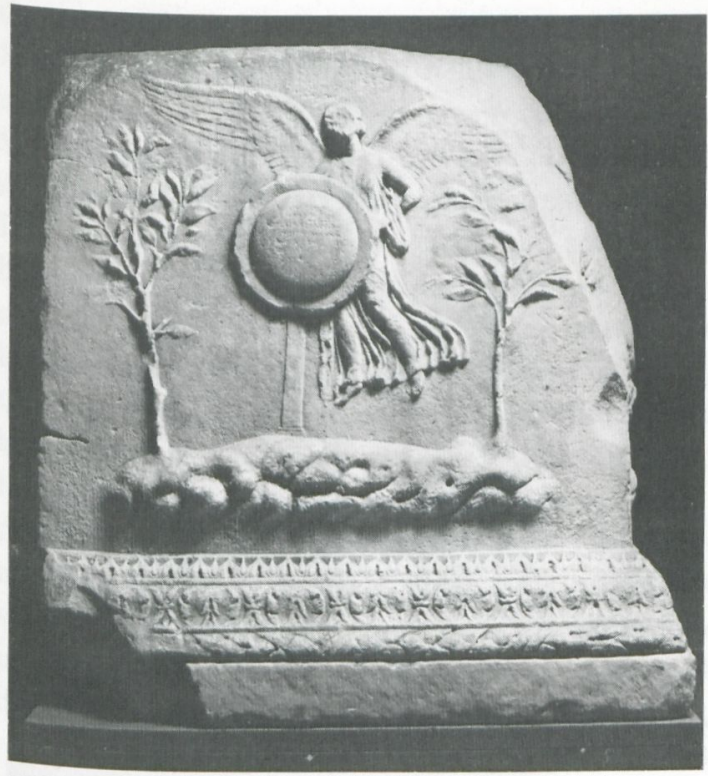

Abb. 17 Vorderseite: Victoria mit dem Schild zwischen den Lorbeerbäumen

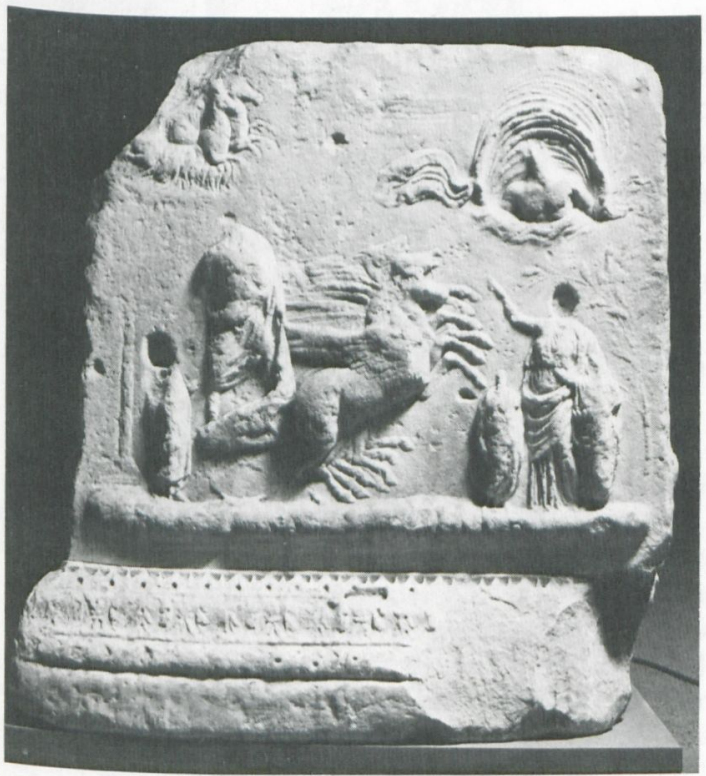

Abb. 19 Rückseite: Apotheose des Romulus

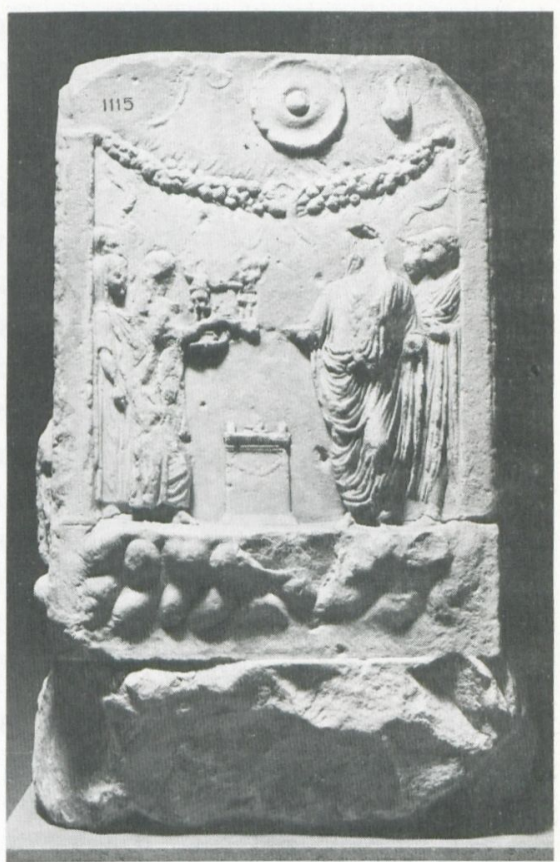

Abb. 18 Linke Seite: Larenopfer des Augustus

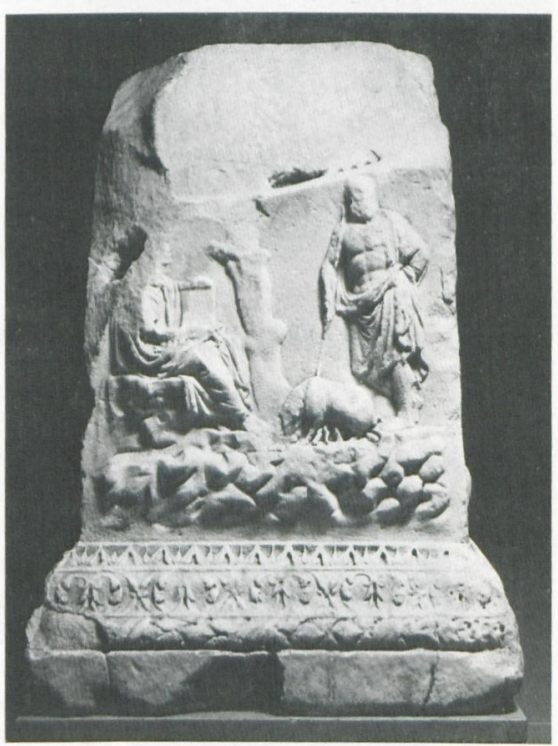

Abb. 20 Rechte Seite:

Die laurentische Sau 
Tafel 4

Abb. 21-22 Fresken aus Pompeji

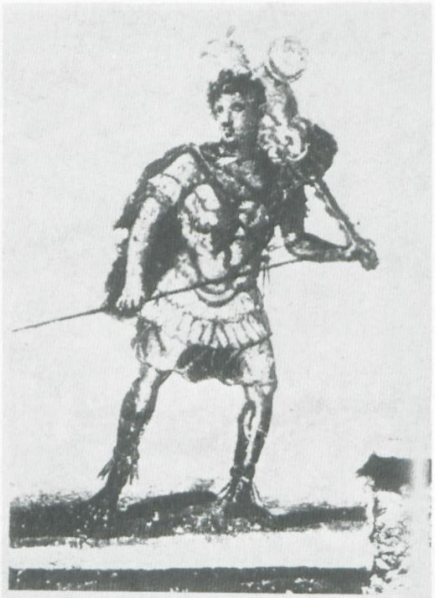

Abb. 21 Romulus

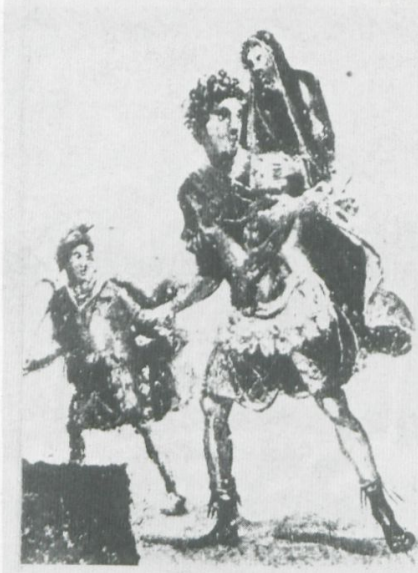

Abb. 22 Aeneas

Abb. 23-24 Ara Pacis, Rom

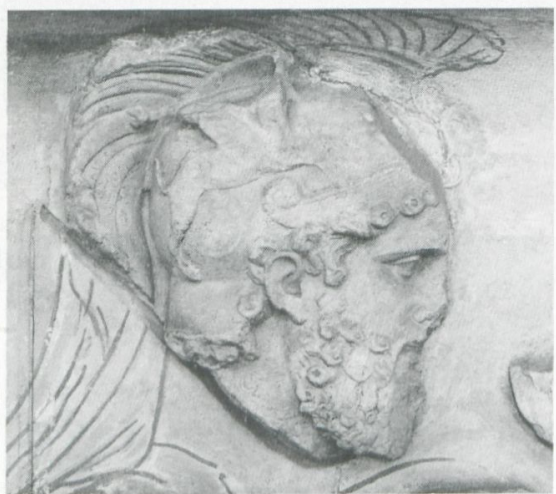

Abb. 23 Kopf des Mars aus dem Lupa-Relief

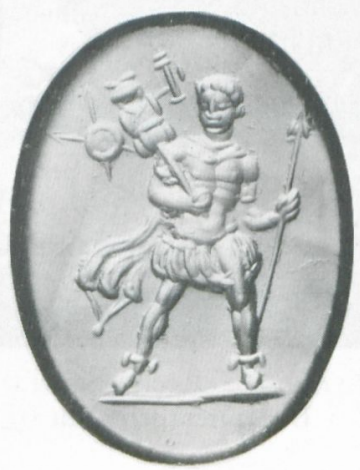

Abb. 25 Karneol, Staatl. Museen Berlin-West: Romulus

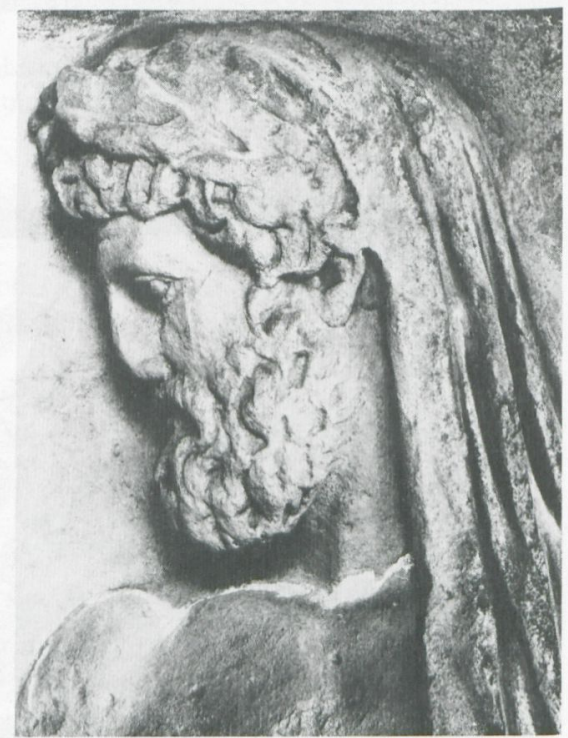

Abb. 24 Kopf des Aeneas aus dem Aeneas-Relief

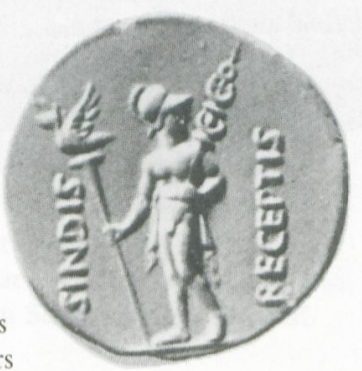

Abb. 26 Denar des Augustus (Rs.): Mars 
then in hohem $\mathrm{Maß}$ veränderbar. Veränderungen ergaben sich aus gewandelten Interessen der Erzähler oder Bildkünstler und ihres Publikums. Die Bereicherung mit neuen aktuellen Zügen war insbesondere so lange ohne grundsätzliche Schwierigkeiten möglich, wie die soziologische Struktur der Gesellschaft sich nicht grundsätzlich änderte. Dies gilt zunächst bis zum Ende der archaischen Zeit. Die griechischen Heldensagen hatten seit jeher große Gestalten zum Thema gehabt, die in ihrer Selbstauffassung und ihren Handlungen kaum durch Institutionen der Gemeinschaft oder gar eines Staates gebunden waren. Von diesen Vorstellungen hatte sich die archaische Polis-Gesellschaft zwar ein Stück weit in Richtung auf bürgerliche Gleichheit entfernt, aber die führenden Vertreter des Adels konnten nicht nur ideologisch, sondern auch in ihren Handlungsmustern weitgehend an die homerischen Helden anknüpfen. ${ }^{7}$ Ein Heros wie Herakles konnte daher neue Züge des aristokratischen Habitus annehmen, indem er mit dem vornehmen Gespann in den Olymp fuhr, auf der Kline lagerte oder gar die Kithara spielte $^{8}$ - dennoch entsprach er noch weitgehend dem alten Ideal des einzelnen ungebundenen Helden und wurde in diesem Rahmen der wichtigste Heros furr den Adel Athens im 6. Jahrhundert v. Chr.

Erst als die historischen Veränderungen um 500 v. Chr. zu einem neuen Maß an politischer Gemeinschaft führten, war ein Zustand der gegenwärtigen Gesellschaft erreicht, der die aktuelle Rezeption der alten Mythen grundsätzlich erschweren konnte. Die politischen Erfahrungen des Staates waren mit der ursprünglichen Gesellschaftsstruktur der Heldensagen kaum mehr kommensurabel. Wenn die alten Mythen im neuen politischen Sinne aktualisiert werden sollten, mußten sie daher stark selektioniert, teils neu formuliert und vielfach auf einer höheren, abstrakteren Ebene interpretiert werden. Dies führte gegenüber dem primären narrativen Gehalt der ursprünglichen Mythen seit klassischer Zeit zumindest im Bereich der Politik zu einer sekundären Sinnschicht der Mythen, die dann auch für die römische Kultur rezipierbar wurde.

Dieser Vorgang kann an dieser Stelle nicht ausreichend beschrieben werden. Nur einige Grundzüge sind kurz zu ertäutern'?

- Für die politische Aktualisierung der Mythen seit dem 5. Jahrhundert gewann

${ }^{7}$ Dazu kurze Andeutungen bei N. Himmelmann, Archäologisches zum Problem der griechischen Sklaverei, Abhandl. Mainz 1971:13,8-10 (618-620). Allgemein zur ,homerischen“ Mentalität im archaischen Adel E. Stein-Hölkeskamp, Adelskultur und Polisgesellschaft, Stuttgart 1989.

${ }^{8}$ LIMC 4 (1988) s. v. Herakles Nr. 1411-1422 (Wagen), 1438-1474 (Kithara oder Lyra), 1483-1523 (Symposion). Sehr viel weiter gehende Deutungen des Herakles, die z. T. viel stärker "politische" Züge annehmen (m. E. anachronistisch), bei J. Boardman in verschiedenen Arbeiten, zuletzt: Herakles, Peisistratos and the unconvinced, Journ. Hell. Stud. 109 (1989) 158f. Dazu kritisch W. G. Moon (Hrsg.), Ancient Greek Art and Iconography, Madison 1983, 97-118; H. A. Shapiro, Art and Cult under the Tyrants in Athens, Mainz 1989, Index s. v. Herakles.

${ }^{9}$ Dazu ausführlicher die in Anm. 6 angekündigte Arbeit. Die folgenden Aussagen sollen nur für den Mythos im Kontext der Politik, nicht für den Mythos der klassischen Zeit insgesamt 
der ideelle und exemplarische Aspekt vorrangige Bedeutung. In der demokratischen Gesellschaft war die Berufung auf ererbte Privilegien aufgrund von Ahnenreihen, die in mythische Vorzeit zurückreichten, kaum mehr am Platz. ${ }^{10}$ Genealogische Vorgänger wurden vor allem kollektiv für die Gemeinschaft der Bürger reklamiert, so Theseus für die Athener; persönliches Charisma dagegen konnte nur mit rein ideellen mythischen Leitbildern begründet werden. Die Kataloge der großen Taten Athens in mythischer und jüngerer Vergangenheit, die in politischen Debatten und bei den Epitaphien vorgetragen wurden, beriefen sich zwar im ,genealogischen' Sinne auf die eigenen Vorfahren; aber dabei wurde bereits eine umfassende politische Ideologie der Gegenwart, vor allem die Verteidigung griechischer Lebensordnung gegen barbarische Angriffe und der Schutz bedrängter Griechen vor innergriechischen Gegnern, mobilisiert und in die mythischen Exempla projiziert. ${ }^{11}$ Wenn dann im Bildprogramm des Parthenon neben die Heldentaten gegen die Kentauren, gegen Troia und gegen die Amazonen, die man mehr oder weniger für Athen beanspruchen konnte, der Kampf der Götter gegen die Giganten $\operatorname{tritt}^{12}$, so geht das weit über eine genealogische Legitimation politischer Positionen hinaus und macht den ideellen Charakter des Exempels deutlich. Noch eindeutiger ist in hellenistischer Zeit das vielfigurige Statuenanathem Attalos' II. auf der Athener Akropolis, in dem die pergamenischen Gallierkämpfe in eine Reihe mit den Siegen der Götter gegen die Giganten, der mythischen Athener gegen die Amazonen und der historischen Athener gegen die Perser gestellt waren. ${ }^{13}$ Die Ideologie der Vorkämpferrolle des Griechentums in der Nachfolge Athens verzichtete völlig auf genealogische Legitimation und berief sich rein auf ideelle Werte.

- Diese ideologische Rezeption des Mythos hatte weiterhin zur Folge, daß nicht mehr die mythischen Personen und Ereignisse als solche und in ihrem ganzen

gelten. Pauschale Betrachtungsweisen „des Mythos der Klassik“, ohne Beachtung der verschiedenen konkreten Funktionen, hat die Urteile z. T. stark verunklärt. Schon in der Vasenmalerei liegen die Verhältnisse offensichtlich anders als bei politischen Monumenten. Und für die Tragödie soll hier gewiß kein Rückfall zu der Suche nach punktuellen politischen Anspielungen propagiert werden.

${ }^{10}$ Über die Widerstände gegen genealogisch begründete Ansprüche im 5. Jahrhundert s. T. Hölscher, Die Aufstellung des Perikles-Bildnisses und ihre Bedeutung, Würzb. Jbb. 1 (1975) 187-199, wieder in: K. Fittschen (Hrsg.), Griechische Porträts, Darmstadt 1988, 377-391.

${ }^{11}$ W. Kierdorf, Erlebnis und Darstellung der Perserkriege (Hypomnemata 16), Göttingen 1966, 35-37. 83-110.

${ }^{12}$ F. Brommer, Die Metopen des Parthenon, Mainz 1967. Dasselbe Thema an der Innenseite des Schildes der Athena Parthenos, wo es sich mit dem Amazonenkampf an der Außenseite und dem Kentaurenkampf an den Sandalen der Figur zu einer mythischen Trilogie zusammenschloß: N. Leipen, Athena Parthenos, Toronto 1971, 29f. 41-57.

${ }^{13}$ Paus. 1,25,2; B. Palma, Il piccolo donario pergameno, Xenia 1 (1981) 45-84; T. Hölscher, Die Geschlagenen und Ausgelieferten in der Kunst des Hellenismus, Ant. Kunst 28 (1985) 120-136. 
Umfang Bedeutung hatten, sondern daß es um ganz partielle Aspekte ging. ${ }^{14}$ Wenn das Athen des 5. Jahrhunderts Theseus zum Ideal des attischen Staatsmannes machte, dann war etwa seine Rolle als Heerführer oder als Einiger Attikas gemeint, nicht aber etwa sein monarchischer Rang oder gar sein Frevel gegen Persephone. Für Alexander wurde Herakles zum Vorbild wegen seiner mühevollen Taten und seiner Aufnahme in den Olymp, nicht wegen seines qualvollen Todes; Achill wegen seiner jugendlichen Heldenhaftigkeit, nicht wegen seines kurzen Lebens; Protesilaos, weil er beim Zug gegen Troia als erster auf das asiatische Festland gesprungen war, nicht weil er anschließend gleich ein Opfer seines Mutes wurde. Je ideeller die Rezeption ist, desto selektiver wird der Mythos verstanden. Der faktisch-narrative Bestand gerät vielfach aus dem Blick.

- Das Verhältnis von Mythos und aktueller Gegenwart ist reziprok. Explizites Ziel ist, die Gegenwart durch Vergleich mit und Angleichung an den autoritativen Mythos zu überhöhen. Implizit ist dies aber an die Voraussetzung geknüpft, daß der Mythos der Gegenwart kommensurabel gemacht wird. Damit Theseus im 5. Jahrhundert zum Vorbild des Politikers werden konnte, mußte er erst wie bei Euripides zum Protagonisten der Demokratie gemacht werden ${ }^{15}$; damit Achill zum Leitbild Alexanders wurde, mußte er erst dessen Heldentypus annehmen. ${ }^{16}$ Um die ideelle Verwandtschaft der Gegenwart mit dem Mythos zu behaupten, wird tatsächlich ideell der Mythos der Gegenwart angeglichen. Der Mythos liefert die Autorität, die Gegenwart die ideologischen Inhalte.

- Die Funktion des Mythos beschränkt sich nicht auf die reine Projektion aktueller Ideologie in die autoritative Vorzeit, die Vergangenheit wird nicht einfach zum ideologischen Double der Gegenwart gemacht. Eine wichtige Funktion ist die ,Auslagerung' von Aussagen, die man explizit über die Gegenwart nicht machte, auf die Ebene des Mythos. Auf den Vasenbildern des 5. Jahrhunderts mit den zeitgenössischen Perserkämpfen erscheinen die orientalischen Gegner zwar gelegentlich durch unvornehme Haltungen und krasse Unterlegenheit in negativem Licht, aber nicht in moralisch-religiöser Verschuldung. ${ }^{17}$ Eben dieser Vorwurf wird aber in Darstellungen von Kentaurenkämpfen erhoben, wo die Unholde das Hochzeitsfest sprengen, sich der Festgeräte bemächtigen und Frauen und Knaben bedrängen. ${ }^{18}$ Religiöser Frevel und seine Vereitelung, die in der Ideologie der

${ }^{14}$ Zum Folgenden schon T. Hölscher, Griechische Historienbilder des 5. und 4. Jahrhunderts v. Chr., Würzburg 1973, 72 .

${ }^{15}$ Eur. suppl. 399-456.

${ }^{16}$ Hölscher (1971) 43-51.

${ }^{17}$ T. Hölscher, Griechische Historienbilder (Anm. 14), 38-49; W. Raeck, Zum Barbarenbild in der Kunst Athens im 6. und 5. Jahrhundert v. Chr., Bonn 1981, 101-163.

${ }^{18}$ Dazu Thomas (1976) 47-57. 
Perserkriege durchaus eine Rolle spielten ${ }^{19}$, werden in den Bildwerken nicht auf der Ebene der Gegenwart formuliert, sondern in einen Mythos transponiert, der als Vorläufer der gegenwärtigen Vorgänge gilt.

- Unter ideologischen Gesichtspunkten können Mythen zu Bildprogrammen zusammengestellt werden, die faktisch überhaupt nichts miteinander zu tun haben. Im Zeustempel von Olympia hat der Maler Panainos eine Umschrankung des Zeusbildes des Phidias mit Bildern von Atlas und Herakles, Theseus und Peirithoos, Herakles mit dem Löwen, Aias und Kassandra, Hippodameia mit Sterope, Prometheus mit Herakles, Achill mit Penthesilea, zwei Hesperiden sowie Hellas und Salamis geschmückt, offenbar als Exempla ethischer Verhaltensweisen. ${ }^{20}$ Ähnlich heterogene Mythen waren am Tempel der Apollonis, der Mutter Attalos' II. und Eumenes' II., in Kyzikos unter dem Gesichtspunkt der Liebe von Söhnen zu ihren Eltern, besonders ihren Müttern, zusammengestellt. ${ }^{21}$ Auch hier tritt unter ideellen Vorgaben der sachliche Zusammenhang der Mythen in den Hintergrund.

- Die Auflösung des narrativen Zusammenhangs findet sich sogar bei einzelnen Mythen. Auf einer Lekythos um 420 v. Chr. in Neapel mit einer Amazonenschlacht nehmen auf Seiten Athens neben Theseus auch Phylakos und Teithras, die Heroen zweier attischer Demen, sowie Phaleros und Mounichos, die Archegeten der zwei Häfen Athens, teil. ${ }^{22}$ Zumindest die Teilnahme des Mounichos, der ein Enkel des Theseus war, an dem Kampf ist rein faktisch gar nicht möglich. Der Vasenmaler hat, ohne Rücksicht auf die mythische Wirklichkeit, Gestalten eingesetzt, die Athen als politisches Gebilde charakterisieren sollten; dazu gehören vor allem auch die Heroen der Häfen, die Athens Seemacht in mythische Vorzeit zurïckführen konnten. Die Ideologie sprengt hier die narrative Stimmigkeit des Mythos.

- Indem die Mythen zu Leitbildern der Gegenwart funktionalisiert werden, gibt sich die Gegenwart den Anschein mythischer Größe. Die attischen Tatenkataloge schließen sich zu einem Konzept zusammen, das man - in einem neuzeitlichen Sinn des Wortes - als ,Mythos Athen` bezeichnen könnte. Ähnlich hat man bei Augustus von einem ,Staatsmythos' gesprochen. ${ }^{23}$

${ }^{19}$ In der Vasenmalerei finden sich nur spät solche Bilder von Persern: K. Schauenburg, Siegreiche Barbaren, Athen. Mitteil. 92 (1977) 99f. Anders Raeck, a.a.O. (Anm. 17), $107 \mathrm{f}$.

${ }^{20}$ Paus. 5,11,4-6; M. Volcker-Janssen, Klassische Paradeigmata. Die Gemälde des Panainos im Zeus-Tempel zu Olympia, Boreas 10 (1987) 11-31.

${ }^{21}$ Ant. Pal. 3,1-19; H. Froning, Marmor-Schmuckreliefs mit griechischen Mythen im 1. Jahrhundert v. Chr. Mainz 1981, 40-47.

${ }^{22}$ J.D. Beazley, Attic Red-Figure Vase Painting, Oxford ${ }^{2} 1963,1074$ f., Nr. 6; E. Simon - M. Hirmer, Die griechischen Vasen, München ${ }^{2} 1981$, Taf. 220; U. Kron, Die zehn attischen Phylenheroen. Geschichte, Mythos, Kult und Darstellung, Berlin 1976, $164 \mathrm{f}$.

${ }^{23}$ Zur Bildung des kollektiven Singulars, der Mythos' habe ich keine erhellende Arbeit gefunden. Zum ideologisierten Begriff des,Mythos‘ im 20. Jahrhundert s. G. Marchal, unten S. $204 \mathrm{ff}$. 
In Rom und Etrurien sind Mythen unter analogen Voraussetzungen wie in Athen Themen politischer Monumente geworden, wenngleich etwa anderthalb Jahrhunderte später. Wie in Athen die Folgeerscheinungen der Kleisthenischen Reformen und die großräumige Rolle des Seebunds, so brachte in Rom die Neuformierung der Gesellschaft nach den Ständekämpfen und die Expansion zur Großmacht eine neue Bewußtheit politischen Handelns und Planens mit sich, die sich in der Entstehung einer politischen Repräsentationskunst äußerte. ${ }^{24}$ Wie in Griechenland waren in Rom mit diesem Prozeß die Gattungen des politischen Denkmals, der öffentlichen Ehrenstatue, des Historienbildes und schließlich der Geschichtsschreibung verbunden. Gleichzeitig entstanden die großen Staatstempel für die Kulte politischer Personifikationen wie Concordia, Salus, Victoria, Fides, Honos und Virtus, durch die Rom eine Art politisch-ideologischer Topographie erhielt. Politik wurde als Sache sui generis begriffen und zur Darstellung gebracht. Im Zuge dieses Prozesses wurde auch die mythische Vergangenheit für die Politik mobilisiert.

Im Jahr 296 v. Chr. stifteten die Brüder Cn. und Q. Ogulnius auf dem Forum eine bronzene Statuengruppe der Wölfin mit den Zwillingen. ${ }^{25}$ Bald darauf wurde das Motiv auf römischen Didrachmen aufgenommen (Abb. 1). ${ }^{26}$, Kurz vor dem Ausbruch des 2. punischen Krieges sind dann die berühmten Goldprägungen entstanden, auf denen das Bündnis zwischen Aeneas und Latinus als Leitbild für den politischen Zusammenhalt gegen Hannibal beschworen wird (Abb. 2). ${ }^{27}$ Bei beiden Themen steht zunächst die genealogische Bedeutung im Vordergrund doch in dem mythischen Bündnis wird zugleich die abstrakte Ideologie der fides impliziert. In anderen Denkmälern sind ideologische Motive noch ausschließlicher maßgebend: Die Statue des Marsyas, die wohl im 3. Jahrhundert v. Chr. auf

Es wäre zu fragen, ob eine ähnliche Entwicklung wie bei anderen singularisierten Begriffen vorliegt, die im 18. Jahrhundert aufkommen: R. Koselleck, Historia Magistra Vitae, in: H. Braun - M. Riedel (Hgg.), Natur und Geschichte. Karl Löwith zum 60. Geburtstag, Stuttgart 1967, 196-219, wieder in: Ders., Vergangene Zukunft, Frankfurt a. M. 1979, 38-66. Ich weise hier auf das Problem hin, um einerseits klarzustellen, daß dies ein Gebrauch des Begriffs ,Mythos' ist, der nicht antikem Gebrauch entspricht - überall, wo in dieser Arbeit von antiken Mythen die Rede ist, läßt sich ohne Zwang der Plural einsetzen; und um andererseits unten die Frage zu stellen, mit welcher Berechtigung und in welchem Sinn wir heute dennoch von einem ,Staatsmythos'sprechen können.

${ }^{24}$ Hölscher (1978) 315-357; ders., Römische Nobiles und hellenistische Herrscher, in: Akten des XIII. Internat. Kongresses für Klass. Archäologie Berlin 1988, Berlin 1990, 73-84. Dazu wichtig K.-J. Hölkeskamp, Die Entstehung der Nobilität, Stuttgart 1987, bes. 204-240.

${ }^{25}$ Liv. 10,23,11. - Dulière (1979) 43-67; Coarelli (1985) 87-123.

${ }^{26}$ Crawford (1974) Nr. $20 \mathrm{f}$.

${ }^{27}$ Crawford (1974) Nr. 28/1-2; 29/1-2. 
dem Forum aufgestellt wurde, entwickelte sich zu einem Symbol der libertas, das auch von anderen Städten übernommen wurde. ${ }^{28}$ Und die Bildnisse des Pythagoras und des Alkibiades, die seit den Samnitenkriegen am Comitium standen, führten zwar nicht bis in die Vorzeit der Heldensage zurück, stellten aber den Römern am Platz ihrer politischen Entscheidungen quasi-mythische Exempla von sapientia und fortitudo, also militärischer virtus vor Augen. ${ }^{29}$ Ohne jede genealogische Verbindung werden hier rein ideelle Leitfiguren beschworen. Die Gestalten der Vergangenheit repräsentierten ähnliche öffentliche Wertbegriffe, wie sie durch die Tempelgründungen damals zu Gegenständen des Staatskults gemacht wurden.

Zweifellos ist diese Funktionalisierung des Mythos damals im Zug einer allgemeinen Welle der Hellenisierung aus Unteritalien und letzten Endes aus Griechenland rezipiert worden. ${ }^{30}$ Wie umfassend solche Rezeption gleichzeitig in Etrurien sein konnte, zeigt das Bildprogramm der Tomba François in Vulci (3. Viertel 4. Jahrhundert). ${ }^{31}$ Obwohl die Bilder, als Schmuck des Grabes eines der führenden Männer der Stadt, keine ,öffentliche' Funktion hatten, müssen sie doch zumindest teilweise auf große politische Denkmäler zurückgehen. Der Grabherr Vel Saties ist hier in ein vielschichtiges historisches und mythisches Bezugssystem gestellt, das seine politische Ideologie repräsentiert: Berühmte Vorfahren, die seinen sozialen Rang dokumentieren; Helden der archaischen Geschichte von Vulci, darunter die Brüder Vibenna und Macstarna, die gegen eine Koalition von Gegnern, darunter ein Tarquinius in Rom, obsiegen, also ein historischer Referenzpunkt in den gegenwärtigen Auseinandersetzungen Vulcis mit Rom; gegenüber die Abschlachtung der jungen Troianer durch Achill, ein mythisches Exempel der Rache an den Troianern, das wiederum gegen deren Nachfahren, die Römer, gerichtet war; schließlich, als Pendant zu Vel Saties, die alten Helden Phoinix und Nestor als Muster von Würde und Altersweisheit. ${ }^{32}$ Alle diese Phänomene haben griechische Wurzeln, aber man wird nicht leicht ein einzelnes mythisch-historisches Bildprogamm in Griechenland nachweisen, das so komplex und zugleich so konsequent konzipiert ist wie die Tomba François.

${ }^{28}$ M. Torelli, a.a. O. (Anm. 2) 95-106, bes. 105; Coarelli (1985) 91-119, bes. 110.

${ }^{29}$ Plin. nat. 34,26: Plut. Numa 6. - Hölscher (1978) 340 f.; F. Zevi, Considerazioni sull'elogio di Scipione Barbato, Studi Miscellanei 15 (1970) 65-73.

${ }^{30}$ Dazu allgemein Hölscher (1978) 350-357; ders., Akten a. a. O. (Anm. 24) 74-79.

${ }^{31}$ F. Messerschmidt - A. von Gerkan, Die Nekropolen von Vulci (Jahrb. Dtsch. Arch. Inst., Ergänz.-Heft 12), Berlin 1930, 62-163; F. Coarelli, Le pitture della Tomba François a Vulci: una proposta di lettura, Dial. Archeol. 3. ser., 1:2 (1983) 43-69; F. Buranelli, La tomba Francois di Vulci, Rom 1987.

${ }^{32}$ Dazu F. Zevi, a.a.O. (Anm. 29) 70, der auf die parallelen Phänomene in Rom, die Elogia der Scipionen-Sarkophage und die Statuen des Pythagoras und des Alkibiades, hinweist. 
Die politische Situation der späten Republik hat dann zu bezeichnenden krisenhaften Veränderungen gefuihrt. Insbesondere die partikulären, divergierenden Interessen und Ansprüche einzelner Politiker fanden ihren Ausdruck in einer höchst disparaten Aktualisierung verschiedenster Mythen. Wichtigstes Zeugnis sind die Münzen, auf denen die Prägebeamten seit dem 2.Jahrhundert v. Chr. ein wahres Feuerwerk von Bildthemen zur Unterstützung persönlicher Ambitionen entfachten. ${ }^{33}$ Hatte die mittlere Republik noch einen relativ kollektiven Bezug zum Mythos entwickelt, so ging diese Gemeinsamkeit der Themen jetzt verloren. ${ }^{34}$

Schon im frühen 2. und dann wieder im frühen 1.Jahrhundert v. Chr. prägten Angehörige der gens Mamilia mit dem Bild des Odysseus (Abb. 3), nicht weil dieser eine allgemeine Verbindung des Westens mit der griechischen Welt begründete, sondern weil die Familie sich von Telegonos, einem Sohn des Odysseus und der Kirke, herleitete. ${ }^{35}$ Ähnlich setzte um 60 v. Chr. P. Plautius Hypsaeus die Götter Neptun und Leuconoe auf seine Denare, weil diese von seiner Familie als Ahnen reklamiert wurden (Abb. 4-5). ${ }^{36}$ Die beiden Beispiele zeigen zum einen, $\mathrm{da} \mathrm{zu}$ dieser Zeit der griechische Mythos nicht nur in den gängigen Hauptsagen, sondern in sehr beträchtlichem Umfang rezipiert und mit großer Findigkeit nach brauchbaren Überlieferungen durchforstet worden war, ein Ergebnis der neuen Hellenisierungswelle seit der Eroberung Griechenlands im frühen 2. Jahrhundert v. Chr.; zum zweiten, in wie persönlicher Weise die Mythen damals zur Verfolgung persönlicher Interessen eingesetzt wurden; schließlich, wie exklusiv diese Art der Selbstdarstellung damals auf ein gebildetes Publikum zugeschnitten war. ${ }^{37}$ All dies sind Züge, die in dieser Zeit allgemein verbreitet waren.

Daneben, und in demselben Sinn, wurde auch die eigene römische Frühzeit mobilisiert. Angehörige der gens Marcia stellten auf ihren Prägungen ihren Ahnherrn Ancus Marcius dar ${ }^{38}$, L. Pomponius $\mathrm{Molo}^{39}$ und Cn. Calpurnius Piso ${ }^{40}$ prägten mit dem Bild des Numa, auf den sie sich über dessen Söhne Pompo bzw. Calpurnius zurückführten. In allgemeinerem Sinn dokumentierte L. Titurius

${ }^{33}$ Beste allgemeine Analyse dieser Entwicklung bleibt A. Alföldi, The main aspects of political propaganda on the coinage of the Roman republic, in: Essays in Roman Coinage Presented to H. Mattingly, Oxford 1956, 63-95; dazu Crawford (1974) 2, 725-744.

${ }^{34}$ Zum Folgenden T.P. Wiseman, Legendary genealogies in late-republican Rome, Greece $\mathcal{E}$ Rome 21 (1974) 153-164. $362 / 1$

${ }^{35}$ Crawford (1974) 149/1-5 (mit Quellen zur behaupteten Genealogie der gens Mamilia);

${ }^{36}$ Crawford (1974) 420/1-2 (mit Quellen zur Genealogie).

${ }^{37}$ Dazu T. Hölscher, Staatsdenkmal und Publikum, Xenia 9 (1984) 12-19.

${ }^{38}$ Crawford (1974) 346/1.3-4; 425/1.

${ }^{39}$ Crawford (1974) 354/1.

${ }^{40}$ Crawford (1974) 446/1. 
Sabinus, entsprechend seinem Cognomen, seine prätendierte Herkunft mit Bildmotiven aus den Auseinandersetzungen zwischen Rom und den Sabinern in der Gründungszeit der Stadt: auf den Vorderseiten jeweils mit dem Kopf des Titus Tatius, auf den Rückseiten mit dem Raub der Sabinerinnen und der Bestrafung der Tarpeia (Abb. 6-8). ${ }^{41}$

Solche Mythen, griechische wie römische, bezeugen die Bedeutung genealogischer Aspekte, die auf die gentilizische Struktur der politischen Ansprüche in dieser Zeit zugeschnitten sind. Sie bezeugen aber auch den partikulären Charakter dieser politischen Mythologie. Jede Familie versucht auf ihre Weise, irgendeinen Anschluß an die Fransenränder der griechischen Mythenkreise herzustellen. $\mathrm{Zu}$ einem eigenen römischen Mythenkreis schließen sich diese mythologischen Splitter nicht zusammen; ein integrierender ,Staatsmythos" ist schon gar nicht in Sicht. Die gemeinsamen Heroen Roms, Aeneas und Romulus, spielen kaum eine Rolle. $^{42}$

Ambitiösere Politiker, die eine breitere Wirkung anstrebten, haben deshalb stärker die ideellen Aspekte von Mythen in den Vordergrund gerückt. Der Censor, der das bekannte Denkmal München-Paris in Auftrag gegeben hat, hat offenbar seine Erfolge als Flottenkommandant mit dem Hochzeitszug des Neptun und der Salacia geschmückt, wobei genealogische Herleitung wahrscheinlich nicht im Spiel war (Abb. 12) ${ }^{43}$ Die Geschichte der Brüder von Katane, die ihre Eltern vor einem Ausbruch des Aetna gerettet hatten, ist auf Prägungen des M. Herennius vielleicht noch unter genealogischen Aspekten dargestellt (Abb. 9) ${ }^{44}$, doch bei Sex. Pompeius diente dasselbe Thema wohl vor allem zum Exempel für pietas (Abb. 10)..$^{45}$

Offensichtlich aber waren auch solche Bilder zu partikulär, um breitere Akzep$\operatorname{tanz}$ zu finden. Es war ein grundsätzliches Dilemma, das sich fast zwangsläufig ergab, wenn man in einer polyzentrischen Gesellschaft eine Sonderposition zu begründen suchte: Entweder wählte man spezifisch persönliche, vorzugsweise genealogische Motive, dann erwiesen sie sich leicht als zu exklusiv und partikulär, um nennenswerte Wirkung zu erzielen. Oder man wählte bekannte, die Gemein-

${ }^{41}$ Crawford (1974) 344/1-2.

${ }^{42}$ Nur Wölfin und Zwillinge, bezeichnenderweise relativ früh: Crawford (1974) 255/1; 267/1.

${ }^{43}$ H. Kähler, Seethiasos und Census, Berlin 1966. Ikonographische Tradition des Seethiasos für Seesiege: T. Hölscher, Censorendenkmal München-Paris, Arch. Anz. (1979) 338-340. Die genealogische Deutung von Wiseman a. a. O. (Anm. 34) 160-164 scheint mir nicht überzeugend: Der Seethiasos hat als Zeichen von Seeherrschaft eine ältere Tradition. Und die Sesterze des M. Antonius und L. Calpurnius Bibulus (38 v. Chr.) stellen Antonius und Kleopatra als Meeresgötter in der Hippokampenquadriga dar, ohne daß Genealogie dabei eine Rolle spielte: K. Schefold, Zur Basis des Domitius Ahenobarbus, in: Essays in Memory of K. Lehmann, New York 1964, 285-287.

${ }^{44}$ Crawford (1974) 308/1.

${ }^{45}$ Crawford (1974) 511/3. 
schaft betreffende und ideell ergiebige Motive, dann waren sie meist nicht auf einen einzigen Staatsmann und seine spezifischen Ambitionen zu beziehen.

Die Lösung wird bei Caesar deutlich: Er hat mythische Gestalten, die für ganz Rom zentrale Bedeutung hatten, speziell auf sich zu beziehen vermocht. Venus war als Göttin von Sieg und Charisma (felicitas) von allen großen Feldherren des 1. Jahrhunderts v. Chr. verehrt worden - Caesar hat sie als persönliche Ahnherrin exklusiv für sich beansprucht. ${ }^{46}$ Wenn Pompeius geträumt haben soll, daß Caesar ihm seine Göttin abspenstig mache ${ }^{47}$, so ist dieser Alptraum nur so verständlich, daß sein ideeller Anspruch allgemeiner felicitas durch den genealogischen Anspruch seines Gegners übertrumpft wurde. Ähnlich konnte Caesar Aeneas in Anspruch nehmen. Bei dem größten bildkünstlerischen Mythenzyklus der Republik, dem Fries der Basilica Aemilia, sind Thema und Datierung bzw. Auftraggeber umstritten. ${ }^{48}$ Ich halte es immerhin für plausibel, daß neben der Sage des Romulus, mit dem Raub der Sabinerinnen usw. (Abb. 13), auch die des Aeneas dargestellt ist, aus der u. a. wohl die Aufdeckung der Ciste mit den Penaten erhalten ist $\left(\right.$ Abb. 14) ${ }^{49}$; und daß dieser Fries von dem Neubau der Basilica stammt, den M. Aemilius Lepidus ab 55 v. Chr. mit finanzieller Unterstützung Caesars errichtet hat. ${ }^{50}$ Der Fries, der in ähnlicher Weise wie der Telephos-Fries von Pergamon den Römern ihre staatliche Identität in den großen Gründungsmythen vor Augen stellt, wäre somit zugleich über Aeneas exklusiv mit einem führenden Politiker der Gegenwart verbunden. Eindeutig ist die Vereinnahmung des Aeneas durch Caesar dann auf Münzen von 47/46 v. Chr., auf denen der Held seine pietas durch Rettung des Anchises und des Palladium erweist (Abb. 11). ${ }^{51}$ Wie bei Venus hat Caesar ein Thema, das das gesamte Gemeinwesen betraf, genealogisch für sich monopolisiert, dabei aber den aktuellen ideologischen Aspekt der pietas in den Vordergrund gerückt. Sex. Pompeius, der diesem Bild einige Jahre später das der

${ }^{46}$ Schilling (1982) 301-324.

${ }^{47}$ Plut. Pomp. 68,2.

${ }^{48}$ G. Carettoni, Il fregio figurato della Basilica Emilia, Riv. Ist. Naz. Arch. e Stor. Art. 10 (1961) 5-78; E. Simon, Fragmente vom Fries der Basilica Aemilia, in: W. Helbig, Führer durch die öffentlichen Sammlungen klass. Altertümer in Rom, Bd. 2, Tübingen ${ }^{4} 1966$, Nr. 2062. Zur Deutung T. Hölscher, in: AA. VV. (1988) 380-382. Erst nach Abschluß des Manuskripts wurde mir P. Kränzle, Die zeitliche und ikonographische Stellung des Frieses der Basilica Aemilia, Hamburg 1991, zugänglich, mit schwach begründeter Datierung auf $78 \mathrm{n}$. Chr.

${ }^{49}$ Carettoni, a.a.O. (Anm. 48) 11 fig. 6. Von Simon als Altar des Consus im Rahmen des Romulus-Mythos gedeutet, wegen der Reifen unwahrscheinlich.

${ }^{50}$ Die Datierung in republikanische Zeit ist nicht mehr strittig. R. Bianchi Bandinelli $-\mathrm{M}$. Torelli, L'arte dell'antichità classica II: Etruria - Roma, Turin 1976, Kap. Arte Romana Schede Nr. 49 haben den Fries erstmals dem Neubau von 78 v. Chr. zugewiesen. Die Flachheit der Platten und der Stil scheinen mir eher dafür zu sprechen, daß er erst beim Bau von 55 v. Chr. in das bestehende Gebälk eingesetzt wurde.

${ }^{51}$ Crawford (1974) 458/1. Bald darauf im Umkreis des Octavian von L. Livineius Regulus übernommen: Crawford (1974) 494/3. 
Brüder von Katane entgegensetzte (Abb. 10), stand damit auf verlorenem Posten. In der historischen Situation, die rapide auf die monarchische Sonderstellung des fuihrenden Politikers hinführte, war Caesars Verbindung genealogischer und ideologischer Mythen zukunftsweisend.

VI.

Augustus hat aus diesen Erfahrungen klare Konsequenzen gezogen und die politische Funktion von Mythen für die folgenden Jahrhunderte geprägt.

Zunächst wurde in seinem Umkreis eine geradezu virtuose Findigkeit entwikkelt, mit der in den verschiedensten Sagen Züge entdeckt wurden, die auf den Princeps bezogen werden konnten. Theseus kämpft im Giebel des Apollo-Tempels beim Circus Flaminius gegen die Amazonen als Protagonist gegen den Osten. ${ }^{52}$ Diomedes erscheint auf Gemmen als Retter des römischen Palladium und Garant der salus publica (Abb. 15). ${ }^{53}$ Orestes ist auf einem Schmuckrelief Prototyp des Rächers für den Vater im Dienst des Apollo. ${ }^{54}$ Augustus' Schutzgott selbst erweist seine Macht an den Türreliefs des palatinischen Tempels gegen die Niobiden $^{55}$, auf Campana-Reliefs aus demselben Tempel im Kampf um den Dreifuß gegen Antonius' Patron Hercules (Abb. 16) ${ }^{56}$, auf einem Wangenaltar in Arles im Streit gegen Marsyas. ${ }^{57}$ Die Reihe läßt sich verlängern. Im Grund sind fast alle Götter und wichtigeren Helden irgendwo einmal mit Augustus in Beziehung gesetzt worden. Das entspricht zunächst einer allgemeineren Tendenz der Repräsentationskunst des Augustus: Der Kaiser wird überall und unausweichlich präsent gezeigt. Andererseits führt das aber auch zu der Konsequenz, daß diese ganze politische Mythologie mehr und mehr zur unverbindlichen Spielerei geriet. Wenn alles und jedes auf den Kaiser wies, dann war daraus keine spezifische Aussage mehr zu gewinnen. Die Repräsentation wurde zur kleinen Münze, zum gefälligen Dekor. $^{58}$

An den öffentlichen Staatsdenkmälern hat Augustus sich daher mehr und mehr

${ }^{52}$ E. La Rocca, Amazzonomachia. Le sculture del tempio di Apollo Sosiano, Rom 1985.

${ }^{53}$ C. Maderna, Iupiter, Diomedes und Merkur als Vorbilder für römische Bildnisstatuen, Heidelberg 1988, 67-70.

${ }^{54}$ T. Hölscher, Augustus and Orestes, in: Travaux du Centre d'archéologie méditerranéenne de l'Académie Polonaise, Etudes et Travaux 15 (1991) 164-168.

55 Prop. 2,31,12-14.

${ }^{56}$ P. Zanker, Der Apollontempel auf dem Palatin, Anal. Rom. Inst. Dan., Suppl. 10 (1983) 34 f.; E. Simon, Augustus, München 1986, 128 f.; G. Carettoni, Die ,Campana'-Terrakotten vom Apollo-Palatinus-Tempel, in: AA. VV. (1988) 267-272, Nr. 121.

${ }^{57}$ E. Espérandieu, Recueil général des Bas-reliefs de la Gaule romaine, Bd. 1, Paris 1907, $117 \mathrm{f}$, Nr. 138.

${ }^{58}$ Auf diese Fragen will ich an anderer Stelle eingehen. 
auf wenige lapidare Bildmotive konzentriert, die bereits erprobte Autorität hatten und von ihm in der Nachfolge Caesars monopolisiert werden konnten: auf Aeneas und Romulus. ${ }^{59}$ Neben der Ara Pacis bezeugen weitere Monumente diese immer stärkere Vereinheitlichung des Staatsmythos.

Ein rechteckiger Blockaltar im Vatikan (Abb. 17-20) $)^{60}$, aus den Jahren 7-2 v. Chr., der in den Umkreis des Herrscherkults gehören muß, zeigt an der Frontseite Hinweise auf den lebenden Kaiser: Victoria zwischen den Lorbeerbäumen, die den clupeus virtutis an einen Pfeiler setzt. Die Gegenseite dazu bildet die Szene einer Apotheose, offenbar des Romulus in Feldherrnrüstung, der mit einem Gespann geflügelter Pferde in den Himmel auffährt, wo ihn Sol und Iuppiter erwarten. ${ }^{61}$ Auf einer Schmalseite dagegen stiftet Augustus die Statuetten der Laren für deren neu gegründeten Kult auf der Velia. Als Gegenbild dazu erscheint auf der anderen Seite Aeneas mit der lavinischen Sau und erfährt von einem Seher die Zukunft Roms. Wie an der Ara Pacis stehen Aeneas und Romulus als Leitbilder von pietas und virtus, diesmal über die Achsen des Altars explizit auf die entsprechenden Tugenden des Kaisers bezogen. Der deutlichere Hinweis dieser Bilder auf den Princeps hängt wohl mit der Funktion des Altars im Herrscherkult zusammen. Entsprechend deuten die mythischen Szenen eindeutiger als an der Ara Pacis auf Augustus: Die Prophezeiung, die Aeneas erhält, soll zweifellos bis zur Gegenwart vorausweisen; und in der Apotheose des Romulus ist offensichtlich die des Augustus antizipiert.

Schließlich das Forum Augusti. ${ }^{62}$ Hier waren in den Hallen, die den Platz einfaßten, Bildnisgalerien der summi viri der bisherigen Geschichte Roms aufgestellt, antithetisch geteilt in Angehörige der gens Iulia und Mitglieder der übrigen Nobilität. Beide Reihen hatten ihr Zentrum in den mythischen Archegeten Aeneas und Romulus, die in den Mittelnischen der beiden Exedren standen. Auch hier war der ideologische Kontext für die Wahl der Bildmotive bestimmend, die in Nachklängen überliefert sind (Abb. 21-22): Da der Tempel nach der Schlacht von Philippi als Denkmal der vollzogenen Rache für den Mord an Caesar errichtet worden war, wurde Aeneas als Retter des Anchises mit Iulus Ascanius an

${ }^{59}$ Wie stark Octavian schon bald nach Actium, obwohl er den Namen Romulus nicht annehmen wollte (Suet. Aug. 7,2), doch die Figur des Stadtgründers exklusiv für sich beanspruchte, geht aus seinem Vorgehen gegen M. Licinius Crassus 29 v. Chr. hervor, den er hinderte, (wie Romulus) die spolia opima zu weihen: E. Groag, RE 13:1 (1926) 283 f., s. v. Licinius (Crassus) Nr. 58.

${ }^{60}$ P. Zanker, Der Larenaltar im Belvedere des Vatikans, Röm. Mitteil. 76 (1969) 205-218; R. Cappelli, L'altare del Belvedere, Ann. Fac. Lett. Fil. Perugia 22 (1984-85) 89-101; T. Hölscher, in: AA. VV. (1988) 394-6, Nr. 223.

${ }^{61}$ Deutung auf Romulus bei U. Geyer, Der Adlerflug im römischen Konsekrationszeremoniell, Bonn 1967, 15 f. Ausführlich demnächst H. Prückner.

${ }^{62}$ P. Zanker, Forum Augustum (o. J.); demnächst M. Spannagel, Rache und Prinzipat, Diss. Heidelberg 1984. 
der Seite dargestellt; und da die Anlage weiterhin das Zentrum des römischen Kriegsruhms bleiben sollte, wurde Romulus als Triumphator mit den spolia opima in Form eines Tropaeums gegenübergestellt. Die Gründungslegende der Stadt, das augurium des Romulus, war im Giebel des Tempels selbst zu sehen. Und in der Mitte des Giebels, ebenso wie in den Kultbildern im Inneren der Cella, waren mit Mars und Venus die göttlichen Ahnen der beiden Gründerheroen vereinigt. Der reale Bezugspunkt dieser mythischen Szenerie aber war Augustus selbst, dessen Standbild die Mitte des Platzes bildete.

Es soll hier nicht um eine genaue Aufschlüsselung dieser oft interpretierten Bildwerke und ihrer Botschaften gehen, die auch die entsprechenden Werke der Literatur, insbesondere des Vergil, einbeziehen müßte. Nur einige strukturelle Aspekte dieser Mythenbilder sollen hervorgehoben werden.

Bezeichnend ist zunächst die Reduktion des Mythos auf zwei Gestalten. Beide werden zunehmend in immer wieder denselben Situationen gezeigt: Aeneas mit dem Vater auf den Schultern oder beim Opfer der Sau, Romulus mit Remus bei der Wölfin oder als Feldherr mit Tropaeum. ${ }^{63}$ Ziel ist die Exemplifizierung ideologischer Leitvorstellungen, vor allem pietas und virtus, bei der Lupa dazu aeternitas imperii. ${ }^{64}$ Daraus resultiert die Erstarrung zu symbolischen Typen. Der faktisch narrative Zusammenhang der Gründungsgeschichte tritt in den Hintergrund gegenüber den emblematischen Gestalten, die über Jahrhunderte ständig wiederholt werden, lapidar und statisch wie die gesamte kaiserliche Staatsideologie. Die Reduktion auf wenige Bildtypen, die Fixierung der Bedeutung auf ideologische Schlagwörter, die massenhafte Vervielfältigung und Verbreitung und die Konstanz durch die Zeiten gehören zusammen; sie ergeben jene versteinerte $\mathrm{Au}$ torität, die der römische Staatsmythos anstrebte. ${ }^{65}$

Die sekundäre Sinnschicht, die nun in den Mythen zum Ausdruck gebracht wurde, geriet auch hier vielfach in Widerspruch zu den faktischen Grundlagen des Mythos. Die primäre Gründungsgeschichte hatte auf dem Ordnungsprinzip einer konkreten Genealogie beruht. Unter den Vorgaben der augusteischen Staatsideologie dagegen konnten Götter und Helden des Mythos in ganz neue Konstellationen eintreten. Venus und Mars sind im Bildprogramm des Forum Augusti wie ein Ehepaar verbunden. Ein Paar waren sie tatsächlich schon in der griechischen Frühzeit gewesen, nicht nur in der Episode des Ehebruchs, der das Gelächter der Götter hervorrief, sondern auch in gemeinsamen Kulten. Aber gerade für den augusteischen Staatsmythos waren sie als Mutter des Aeneas und als Vater des

${ }^{63}$ Bildzeugnisse zu Aeneas: F. Canciani, LIMC 1 (1981) 381-396. - Romulus: Dulière (1979); R. M. Schneider, Augustus und der frühe römische Triumph, Jahrb. Dtsch. Arch. Inst. 105 (1990) 167-205, bes. 187-201.

${ }^{64}$ Aeternitas imperii: Dulière (1979) 157-159. 162-166.

${ }^{65} \mathrm{Zu}$ diesen Phänomenen T. Hölscher, Die Geschichtsauffassung in der römischen Repräsentationskunst, Jahrb. Dtsch. Arch. Inst. 95 (1980) 265-321. 
Romulus mit anderen Partnern verbunden; die Darstellung als Paar könnte, so verstanden, fast prekär wirken und bleibt zumindest widersprüchlich. Erst wenn man Venus und Mars im allgemeinen ideologischen Sinn als Stammeltern der Römer sieht, werden sie als Paar plausibel.

Aeneas und Romulus erscheinen in dieser Konstellation wie Brüder. Der genealogische Abstand wird bedeutungslos, wenn die Helden für ideologische Leitbilder stehen, die gleichzeitig, und einander ergänzend, Geltung haben. Es sind gegensätzliche ,Brüder', der Fromme und der Mutige, die gleich bedeutungsvoll zwei verschiedene Rollen des Kaisers präfigurieren.

Darüber hinaus sind Götter und Helden in Altersstufen ausdifferenziert. ${ }^{66}$ Seit Alexander als Ideal des Monarchen den Typus des jugendlichen Helden entwickelt hatte, konnten er und alle seine Nachfolger den Aspekt des väterlichen Herrschers zumindest nicht mehr in ihrer äußeren Erscheinung zum Ausdruck bringen. Für ihre jugendlichen Züge fanden sie göttliche und heroische Leitbilder wie Dionysos, die Dioskuren, Achill oder auch Herakles, die den Herrschern oft ,brüderlich gleichen. ${ }^{67}$ Aber die Eigenschaft als allmächtiger Vater der Untertanen mußte in das Bild von Vatergottheiten, vor allem des Zeus, ,ausgelagert' werden. Der, Vater im Himmel ${ }^{\star}$ einerseits und die konkret agierenden, teils genealogischen, teils ideologischen ,Söhne“ auf Erden andererseits: Diese Struktur hat ihre Wirkung bis zu Gott Vater und Gott Sohn gehabt.

Für Augustus wurden die Leitbilder des würdigen Vaters und des jugendlichen Kriegshelden auf Aeneas und Romulus verteilt. Aeneas, der noch auf den Münzen Caesars und aus dem Umkreis des jungen Octavian als junger Mann den alten Anchises getragen hatte, erscheint nach Actium in den neuen Bildern des Opfers der lavinischen Sau durchweg in würdiger Barttracht (Abb. 24). Romulus dagegen ist der jugendliche Feldherr (Abb. 25). Wieder hängt die Unterscheidung nicht mit der genealogischen Priorität des Aeneas zusammen, sondern sie beruht auf den ideologischen Leitbildern, die die Helden verkörpern: Virtus, die vor allem als Kriegstüchtigkeit verstanden ist, wird bei Romulus mit derselben Jugendlichkeit zum Ausdruck gebracht, die der Princeps in seinen Bildnissen zur Schau stellt; pietas, vor allem gegen die Götter, wird mit väterlicher dignitas verbunden und in das Bild des pater Aeneas ausgelagert.

Von hier aus wird eine merkwürdige Zwiespältigkeit im Bild des Mars verständlich. Der Gott erscheint auf den Münzen, die den Erfolg gegen die Parther feiern, bartlos und in jugendlicher Nacktheit, ein Feldzeichen oder ein Tropaeum auf

${ }^{66}$ Das Folgende soll an anderer Stelle ausführlicher dargelegt werden.

${ }^{67}$ Hölscher (1971) 43-51. 
der Schulter und vielfach in bewegtem Tanzschritt (Abb. 26) ${ }^{68}$ Der Mars der Ara Pacis dagegen, ebenso wie der Mars Ultor des Forum Augusti, trägt einen würdigen Bart (Abb. 23). Der Befund kann nur bedingt im Sinne einer chronologischen Entwicklung vom stürmischen Kriegsgott der späten Republik und der frühen kriegerischen Phase des Octavian zu dem Vatergott der augusteischen Friedenszeit verstanden werden. ${ }^{69}$ Denn zum einen ist es eher unwahrscheinlich, daß eine so folgenreiche ikonographische Neuerung wie die Bärtigkeit des Mars von einem architektonischen Relief wie der Ara Pacis ausgegangen ist; weit eher ist an die Statuengruppe im Pantheon von 25 v. Chr. zu denken, wo Mars jedenfalls bereits in der Rolle als Vater des Romulus und des römischen Volkes, zusammen mit Venus, dargestellt war. ${ }^{70}$ Wenn dies zutrifft, wäre der bärtige Mars also schon eine Schöpfung der frühaugusteischen Zeit. Zum anderen bleibt neben dem neuen Typus des Mars pater weiterhin der jugendliche Mars mit Tropaeum durch die ganze Kaiserzeit erhalten. Beide Vorstellungen sind somit wahrscheinlich seit frühund sicher seit mittelaugusteischer Zeit nebeneinander in Geltung, beide in der Staatskunst. Das Bild des Mars wird also, je nach ideologischer Aussage, in Mars ,Vater‘ und ,Sohn` aufgespalten.

Das sekundäre ideologische System, in das die Mythen gebracht werden, gibt sich darin zu erkennen, daß die primären Konstellationen, Genealogie und konkrete Handlungszusammenhänge, irrelevant und z. T. sogar aufgelöst werden.

${ }^{68}$ H. Mattingly, Coins of the Roman Empire in the British Museum, Bd. 1, London 1923, 60, Nr. 332; 65, Nr. 366-370; 71, Nr. 410-415; J.-B. Giard, Bibliothèque Nationale. Catalogue des monnaies de l'Empire Romain. 1: Auguste, Paris 1976, 250 Index s. v. Mars; E. Simon, LIMC 2 (1984) 528, Nr. 210; Siebler (1988) 156.

${ }^{69}$ Hierzu zusammenfassend E. Simon, LIMC 2 (1984) 554f.; Siebler (1988) 25f. 42-44. 44-48.

${ }^{70}$ Cass. Dio 53,27,2. - E. Simon, LIMC 2 (1984) 511, Nr. 17 vermutet, der Mars des Pantheon (27-25 v. Chr.) sei noch unbärtig gewesen, allerdings nur aus dem Grund, weil Mars mit Bart erstmals an der Ara Pacis (13-9 v. Chr.) nachzuweisen ist. Andererseits meint sie aber auch a. a. O. $554 \mathrm{f}$, daß der bärtige Typus nicht an der Ara Pacis erfunden sei. Als Vorläufer sieht sie (a.a.O. 522 f., Nr. 143; 554) einen Kopftypus mit Helm und Bart an, den sie hypothetisch auf ein vermutetes augusteisches Kultbild im Tempel des Mars vor der Porta Capena (19 v. Chr.?) zurückführt; die Statue im Pantheon komme nicht in Frage, weil damals nach Ausweis der Münzen die bärtige Darstellung des Mars noch nicht üblich gewesen sei. Diese Überlegungen basieren aber auf dem unbeweisbaren Axiom, daß Unbärtigkeit und Bärtigkeit des Mars bis 20 v. Chr. im Sinn einer chronologischen Entwicklung, erst danach als inhaltliches Nebeneinander interpretiert werden müssen. Da über den Tempel an der Porta Capena - trotz F. C. Albertson, An Augustan Temple Represented on an Historical Relief, Am. Journ. Arch. 91 (1987) 441-458 - aus augusteischer Zeit nichts bekannt ist, bleibt hier alles unsicher. Andererseits muß der Mars im Pantheon, das deutlich mit Romulus zusammenhängt (F. Coarelli, Il Panteon, l'apoteosi di Augusto e l'apoteosi di Romolo, Anal. Rom. Inst. Dan., Suppl. 10 [1983] 41-46) bereits väterliche Aspekte gehabt haben. Siebler (1988) 153-156 hat die Bedeutungsverschiebung des Mars zur Vatergottheit im Pantheon erkannt, hat aber daraus keine Konsequenzen für die Vorstellung von der Statue des Gottes gezogen. 
Selbst die Einheitlichkeit der mythischen Gestalt kann, wie bei Mars deutlich wurde, gesprengt werden. Ausgangspunkt ist die aktuelle Gegenwart, deren ideologische Vorgaben dem faktischen Gehalt der Mythen immer inkommensurabler werden: Je stärker die gegenwärtige, sekundäre Sinnschicht wird, desto stärker werden die alten Mythen zersetzt. Gerade darin erweist sich aber die ungebrochene autoritative Kraft der Mythen: Denn obwohl die alten Geschichten und ihre Gestalten immer gezwungener, oft nur mit gesuchten Allegorien, die neuen Inhalte vermitteln, werden sie nicht aufgegeben. Man braucht sie, weil sie allein durch ihr Alter Autorität verbürgen.

Darin ist ein letzter Punkt impliziert: Es geht bei all diesen Manipulationen nicht nur darum, Mythen zu aktualisieren. Wichtiger ist die Gegenseite: daß damit die Gegenwart ,mythisiert' wird. Dies spricht sich freilich leicht aus. In welchem Sinne aber kann man hier von "Mythos" sprechen? Begriffe wie ,Mythos Athen“ oder ,Mythos des Goldenen Zeitalters' weisen zunächst, wie alle derartigen Begriffe, auf eine ausgeprägte Ideologie. ${ }^{71}$ Eine Unterscheidung zwischen ,Staatsideologie‘ und ,Staatsmythos` wäre wohl in dem Sinne zu treffen, daß mit Ideologie ein gedanklich-begriffliches System bezeichnet wird, während mit Mythos eine - und sei es nur metaphorisch - personale oder zumindest bildhafte Vorstellung erweckt wird. Der kollektive Singular ,Mythos' bezeichnet dabei den umfassenden Charakter des Konzepts, das verschiedene Faktoren, d. h. Gestalten, Handlungen und Ideen zusammenschließt. Diese gestalthafte ,mythische Qualität kann der dahinter stehenden Ideologie einen charismatischen Zug geben, kann dadurch die emotionale Wirkung steigern und die Verbreitung fördern.

Für den Begriff des Staatsmythos ist entscheidend, daß die gegenwärtige Geschichte nicht in den Formen der historischen Wahrnehmung und Erinnerung, sondern in Strukturen von Mythen gesehen wird. Dabei stehen zwei Aspekte im Vordergrund. Mythen stellen zum einen grundsätzlich nicht die zufällige Vielfalt kontingenter Ereignisse dar, sondern bestehen in klar strukturierten Sinn-Sequenzen. Damit hängt zum zweiten zusammen, daß die Gestalten des Mythos nicht die diffuse und ambivalente Wesensart individueller Persönlichkeiten besitzen, sondern eindeutig definierte Charaktere sind. Hier sind offensichtliche Unterschiede zwischen historischer Realität und Mythos bezeichnet ${ }^{72}$ : Kein Mythos ließe sich etwa mit der vielschichtigen Kompromißpolitik und den komplizierten

${ }^{71} \mathrm{Zu}$ Mythos als politischem und sozialem Begriff s. Horstmann (1984) 309-311. Allgemein E. Cassirer, Der Mythos des Staates, Zürich 1949; Barthes (1957); Chr. Jamme, Einführung in die Philosophie des Mythos, Bd. 2, Darmstadt 1991, $109 \mathrm{f}$.

${ }^{72}$ Eine Untersuchung über die strukturellen thematischen und narrativen Unterschiede zwischen mythischer Erzählung und historischem Bericht ist mir nicht bekannt geworden. Es ist ein Gemeinplatz, daß die ,Mythen“ von Griechen und Römern als reale Vorgeschichte betrachtet wurden. Dennoch wäre es falsch, die grundsätzliche Verschiedenheit von ,alter Vorgeschichte und ,neuer' Geschichte der eigenen Zeit zu übersehen. 
Verfassungskonstruktionen des Augustus oder mit einem Psychogramm seiner jugendlichen Skrupellosigkeit und seiner späteren patriarchalischen Fähigkeiten konstruieren. Mythisierung der historischen Gegenwart bedeutet also Reduktion auf einfache Handlungssequenzen und klare typische Gestalten. Bei Augustus wird dies in vieler Hinsicht deutlich. Der Kampf und Sieg gegen Antonius als Beginn einer glücklichen Herrschaft eignete sich zu einer solchen Mythisierung, die Geburt als Sohn eines Gottes und die wiederholte wunderbare Rettung aus Gefahren durch die Gunst der Götter ist ein anderes Mythologem. Für beide Motive standen, etwa im Mythos des Orest oder in verschiedenen Mythen von Götterkindern, tatsächlich Vorbilder zur Verfügung, nach denen Augustus interpretiert werden konnte. In einem sehr viel abstrakteren Sinne bedeuteten seine Selbststilisierungen als Neugründer Roms und als Vollender der römischen Geschichte eine mythisch narrative Rolle.

Entsprechend hat Augustus sich aber auch als Person ,mythisch' typisiert: als der Tapfere, der Weise, der Gerechte, Bescheidene und Fromme. Nicht ob er bei dieser oder jener Gelegenheit, in dieser oder jener Hinsicht, mehr oder weniger gerecht, tapfer und weise gehandelt hatte, sollte deutlich werden, sondern es wurde ein pauschales Image konstruiert. Solche klar konturierten pauschalen Leitbilder sind noch keine ,Mythen', sofern zum Begriff des Mythos ein erzählbares Geschehen gehört. Aber es ist deutlich, daß solche Gestalten, wenn man sie handelnd dächte, nicht in den Formen der Zeitgeschichte mit ihren kontingenten Ereignissen, sondern nur in Form von Mythen handeln könnten. Der clupeus virtutis begründet einen solchen ,Mythos', wenn man die vier darauf gerühmten Herrschertugenden virtus, clementia, iustitia und pietas narrativ umsetzt: Es war einmal ein Herrscher, der regierte sein großes Reich mit außergewöhnlicher Stärke, Milde, Gerechtigkeit und Pflichterfuillung gegen Götter und Vaterland. In diesem Sinn kann man wohl von einer ,mythogenen' Gestalt, von "Mythisierung' der Zeitgeschichte und der Gegenwart sprechen. Die Eckpfeiler der mythisch stilisierten Tugenden des clupeus, virtus und pietas, haben in Romulus und Aeneas ihre mythischen Prototypen erhalten.

Auf dieselbe Mythisierung war aber auch die politische Praxis angelegt: Für die Bevölkerung muß die Regierung des Augustus vor allem in Kriegszügen mit spektakulär inszeniertem Aufbruch und entsprechender Rückkehr, mit Staatsakten der Gerechtigkeit und Gesten der Bescheidenheit, mit Gründungen von Tempeln und anderen religiösen Zeremonien sichtbar geworden sein, in denen wieder dieselben ,mythogenen“ Leitbilder proklamiert wurden.

Die Verbindung zwischen zeitgenössischer Geschichte und mythischer Vergangenheit wird durch die sekundäre Sinnschicht der politischen Ideologie hergestellt. Indem die Gegenwart mythisiert, der Mythos aber ideologisch aktualisiert wird, werden beide kommensurabel. Dies System mythogener Leitbilder wurde von Augustus auf langfristige, ,ewige' Geltung hin konzipiert. Dadurch blieben nicht nur die mythischen Protagonisten Aeneas und Romulus über Jahrhunderte hin 
aktuell, sondern Augustus selbst wurde in dem erläuterten Sinn mehr und mehr zu einer ,mythischen' Gestalt mit langer Nachwirkung. Doch das ist eine neue Geschichte.

Wichtiger ist in diesem Zusammenhang eine andere Frage: welche reale politische Funktion hatte diese Mythisierung der Gegenwart? Es wäre sicher falsch, hier das Klischee zu mobilisieren, der Mythos sei Phantasie und Lüge, mit der Augustus über die spannungsreiche Wirklichkeit seiner Regierung hinwegzutäuschen suchte. Denn seine Herrschaft konnte wohl tatsächlich unter diesen Gesichtspunkten gesehen werden, sonst hätte der Staatsmythos nicht so überzeugend gewirkt. Entscheidend ist vielmehr die Struktur der Mythisierung: daß über die vielfältigen, zufälligen, kontingenten Ereignisse, Handlungen und Schicksale ein einfach strukturierter Sinn gelegt wurde. Strukturierung in diesem Sinne bedeutet aber immer Absehen von der Vielfalt des Einzelnen, also eine Verschleierung der Wirklichkeit. Als ideologisches Verfahren der Politik bleibt das zumindest fragwürdig. Denn es ist deutlich, welche Dienste ein solcher Staatsmythos bei der Durchsetzung einer Herrschaft leisten konnte, deren Erfolge mit so enormen Kosten erkauft waren wie die des Augustus.

Nachweis der Abbildungen

Deutsches Archäologisches Institut, Rom: Abb. 13, 14, 17-20, 24. - Glyptothek, München: Abb. 12. - Hirmer Fotoarchiv, München: Abb. 1-3, 6, 9, 11. - Soprintendenza Archeologica di Roma: Abb. 16. - Staatliche Museen, Berlin: Abb. 25. - G. Fittschen-Badura: Abb. 23. - M. H. Crawford, Roman Republican Coinage (1974): Abb. 4, 5, 7, 8. - M.-L. Vollenweider, Die Steinschneidekunst und ihre Künstler in spätrepublikanischer und augusteischer Zeit (1966): Abb. 15. - P. Zanker, Augustus und die Macht der Bilder (1987): Abb. 10, 21, 22. 